\title{
SISTEM INFORMASI PENGELOLAAN DANA BANTUAN OPERASIONAL SEKOLAH (BOS) SMK AL-HASANAIN BERAIM BERBASIS PHP DAN MySQL
}

\author{
${ }^{1}$ Mohammad Taufan Asri Zaen, ${ }^{2}$ Baiq Sri Mardiani \\ Program Studi Sistem Informasi \\ Sekolah Tinggi Manajemen Informatika dan Komputer (STMIK) \\ Jln. Basuki Rahmat No.105 Praya Lombok Tengah \\ 1opanzain@gmail.com, ²baiqsrimardiani@gmail.com
}

\begin{abstract}
School Operational Assistance (BOS) is a government program to provide funds for non-personnel education units, primary and secondary costs as a means of implementing the 9-year compulsory education program. BOS funds are intended to alleviate all forms of education costs for all students. BOS management is currently still using a manual system, and thats no exception at Al Hasanain Beraim Vocational School. This manual management errors and hassle because the BOS revision must go to the Education Office.

Information System (SI) the management of BOS funds was built to facilitate schools. This SI contains an activity plan submission and a one-year budget, and a general cash book for BOS funds that is carried out every semester. This system is built using by PHP language and MySQL database the system development life cycle (SDLC) development method.

This information system can help the school in the process of planning school fund activities (RKAS) every year and preparation of real funds in the form of general cash books (BKU), makes it an easier for administrators to check operational of school assistance funds that have been budgeted for the country's financial statements that produce data accurate and complete and timely.
\end{abstract}

Keywords: Web Applications, BOS, PHP, MySQL, BKU, RKAS, SDLC

\begin{abstract}
Abstrak
Bantuan Operasional Sekolah (BOS) merupakan program pemerintah untuk menyediakan dana bagi unit pendidikan nonpersonalia, biaya primer dan sekunder sebagai sarana pelaksanaan program wajib belajar 9 tahun. Dana BOS bertujuan untuk meringankan segala bentuk biaya pendidikan untuk semua siswa. Pengelolaan BOS saat ini masih menggunakan sistem manual, dan tidak terkecuali di SMK Al Hasanain Beraim. Pengelolaan manual ini menyebabkan sering terjadinya kesalahan dan merepotkan karena revisi BOS harus dilaporkan ke Dinas Pendidikan.

Sistem Informasi (SI) Pengelolaan Dana BOS dibangun untuk memfasilitasi sekolah dalam mengelola keuangan, dan lebih cepat dalam proses mencetak laporan. SI ini memuat pengajuan rencana kegiatan dan anggaran sekolah setiap satu tahun sekali, dan buku kas umum pelaporan dana bos yang di lakukan setiap semester. Sistem ini dibangun menggunakan bahasa pemrograman PHP dan database MySQL menggunakan metode pengembangan siklus hidup pengembangan sistem (SDLC).

Sistem informasi ini dapat membantu pihak sekolah dalam proses perencanaan kegiatan anggaran sekolah (RKAS) setiap tahun dan persiapan pelaporan penggunaan dana aktual secara triwulanan dalam bentuk buku kas umum (BKU), memudahkan admin dalam pengecekan dana bantuan operasional sekolah yang telah dianggarkan sehingga laporan keuangan yang dihasilkan memiliki data yang akurat dan lengkap serta tepat waktu.
\end{abstract}

Kata Kunci: Aplikasi Web, BOS, PHP, MySQL, BKU, RKAS, SDLC 


\section{Pendahuluan}

Bantuan Operasional Sekolah (BOS) adalah program pemerintah untuk penyediaan pendanaan biaya nonpersonalia bagi satuan pendidikan dasar dan menengah sebagai sarana pelaksanaan program wajib belajar 9 tahun. Dalam dunia pendidikan sekarang ini semua biaya operasional peserta didik di biayai oleh BOS. Program BOS bertujuan untuk membebaskan segala jenis biaya pendidikan bagi seluruh siswa SD, SMP negeri dan swasta di Indonesia dari biaya operasional sekolah. BOS atau yang sering dikenal dengan biaya operasional siswa dimaksudkan agar anak yang kurang mampu atau anak yang putus sekolah bisa menikmati pendidikan sekurang-kurangnya selama 12 (dua belas) tahun.

Laporan pengalokasian dana BOS merupakan hal yang sangat penting untuk membantu pemerintah dalam melakukan monitoring dan evaluasi terhadap program pemerintah. Laporan dana BOS berisi semua kegiatan keuangan baik pemasukan maupun pengeluaran yang dilakukan oleh instansi pendidikan yang dalam pembiayaannya menggunakan dana BOS serta penyusunannya dilakukan dalam periode tertentu.

Pengelolaan dana BOS pada saat ini terutama penyusunan laporan pada SMK AlHasanain Beraim masih dilakukan secara manual dimana pengelola harus melakukan copy-paste form yang akan digunakan dari form yang telah disediakan sebelumnya. Hal ini berakibat pada waktu yang cukup lama dalam pembuatan maupun penyimpanan data dan laporan pengalokasian dana BOS.

\section{Tinjauan Pustaka}

Wulandari, dkk (2008) dalam penelitiannya tentang aplikasi pengelolaan dana BOS menyatakan aplikasi dapat meningkatkan efektifitas dan efisiensi sehingga laporan pengelolaan dana BOS akan lebih terstruktur, dan juga memiliki beberapa fungsionalitas diantaranya pencatatan data RAPBS. Aplikasi ini dapat melakukan pengelolaan dana BOS termasuk pengecekan data, penerimaan, serta pengeluaran agar pengelolaan dana BOS dilaksanakan dengan tertib administrasi, transparan, akuntabel, serta terhindar dari penyimpangan.

Prasetyo (2010) dalam penelitiannya tentang laporan dana BOS melalui website menyatakan sistem tersebut dapat menyajikan laporan BOS dalam beberapa langkah kerja, berita pemberitahuan dan penanggung jawab pengelolaan dana BOS tingkat kabupaten kepada pihak sekolah relatif lebih mudah dilakukan melalui sarana website. Sistem dirancang sedemikian rupa sehingga dapat digunakan dengan mudah bagi yang tidak memiliki dasar kemampuan pengoperasian komputer yang tinggi karena memakai model pendekatan yang interaktif, yaitu penggunaan pesan untuk menunjukkan kesalahan bila terjadi dan penggunaan istilah-istilah yang familiar pada website.

Mudrikah (2013) dalam penelitiannya tentang aplikasi laporan dana BOS menyatakan sistem dapat menyajikan realisasi penggunaan dana BOS, rekapitulasi realisasi penggunaan tiap jenis anggaran, laporan keadaan kas dan buku pembantu pajak serta posisi kas. Untuk menghasilkan hasil yang maksimal, dibutuhkan penyesuaian antara sistem dengan manajemen/ instansi (sekolah) sehingga penyusunan aplikasi laporan dana BOS disesuaikan dengan kebutuhan instansi, dan memperbaiki kelemahan dari sistem lama agar lebih tepat dan efisien serta disusun sedemikian rupa hingga menjadi aplikasi yang mudah untuk digunakan.

\section{Bantuan Operasional Sekolah (BOS)}

Menurut Peraturan Mendiknas nomor 69 tahun 2009, standar biaya operasi nonpersonalia adalah standar biaya yang diperlukan untuk membiayai kegiatan operasi nonpersonalia selama 1 (satu) tahun sebagai bagian dari keseluruhan dana pendidikan agar satuan pendidikan dapat melakukan kegiatan pendidikan secara teratur dan berkelanjutan sesuai Standar Nasional Pendidikan. BOS adalah program pemerintah yang pada dasarnya adalah untuk penyediaan pendanaan biaya operasi nonpersonalia bagi satuan pendidikan dasar sebagai pelaksana program wajib belajar.

Secara umum program BOS bertujuan untuk meringankan beban masyarakat terhadap pembiayaan pendidikan dalam rangka wajib belajar 9 (Sembilan) tahun yang bermutu. Secara khusus program BOS bertujuan untuk:

1) Membebaskan pungutan bagi seluruh siswa SD negeri dan SMP negeri terhadap biaya operasi sekolah, kecuali pada rintisan sekolah bertaraf internasional (RSBI) dan sekolah bertaraf internasional (SBI).

2) Membebaskan pungutan seluruh siswa miskin dari seluruh pungutan dalam bentuk apapun, baik di sekolah negeri maupun swasta.

3) Meringankan beban biaya operasi sekolah bagi siswa di sekolah swasta 
Sasaran program BOS adalah semua sekolah SD/SDLB, SMP/SMPLB/ SMPT, dan SD-SMP Satu Atap (Satap), baik negeri maupun swasta di seluruh provinsi di Indonesia yang sudah memiliki Nomor Pokok Sekolah Nasional (NPSN) dan sudah terdata dalam sistem Data Pokok Pendidikan (Dapodik).

\section{Analisa dan Perancangan}

\subsection{Sistem Yang Berjalan}

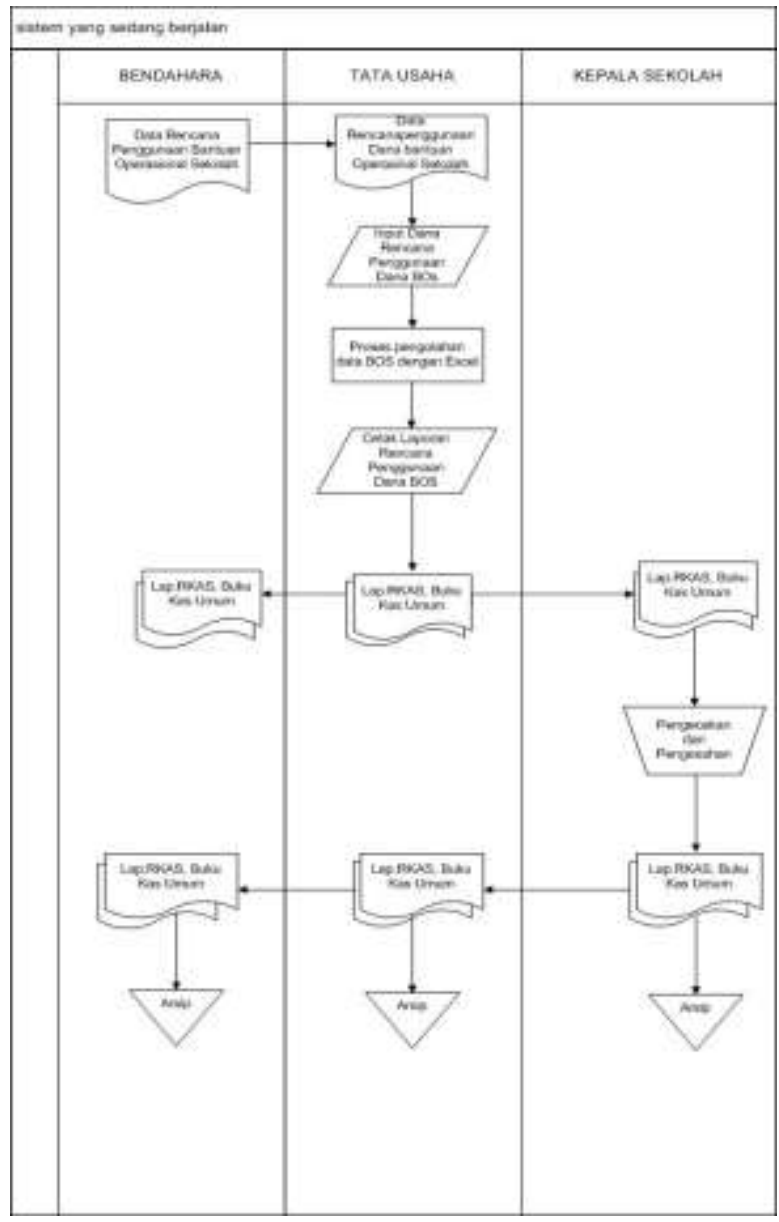

Gambar 4.1 flowmap sistem yang berjalan

1) Bendahara memberikan data rencana penggunaan dana Bantuan Operasional Sekolah kepada tata usaha.

2) Tata Usaha memberikan data rencana penggunaan dana Bantuan Operasional Sekolah dari bendahara yang kemudian diinputkan kedalam sistem dengan menggunakan microsoft excel.

3) Laporan yang telah dibuat kemudian dicetak rangkap tiga dan diperiksa apakah laporan tersebut telah sesuai kebenarannya. Jika laporan belum sesuai maka kepala sekolah memberikan data rencana penggunaan dana BOS ke bendahara. Kemudian bendahara memberikan laporan tersebut kepada tata usaha untuk diinput kembali. Jika laporan telah valid maka laporan tersebut dicetak rangkap tiga, kemudian diserahkan kepada bendahara, kepala sekolah, dan satu sebagai arsip di bagian tata usaha.

\subsection{Sistem yang di usulkan}

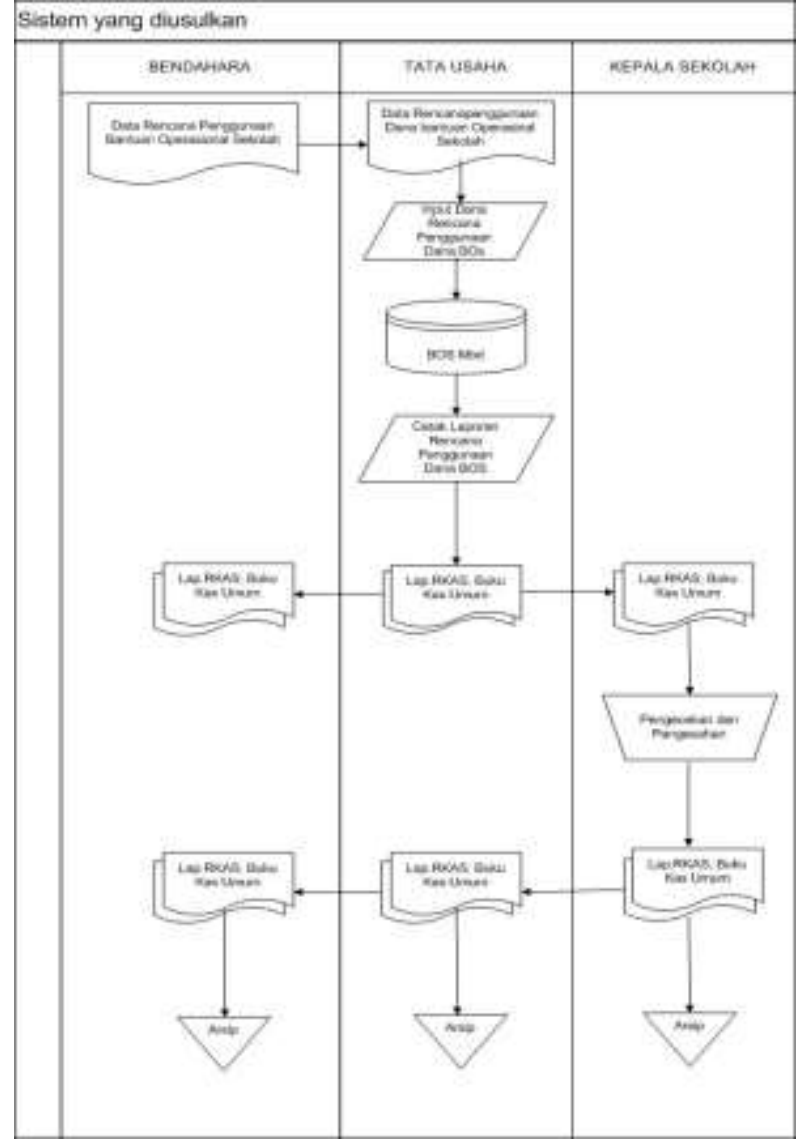

Gambar 4.2 flowmap sistem yang di usulkan

Sistem yang diusulkaan memiliki perbedaan dengan sistem lama karena sistem yang dibuat untuk mencapai pengelolaan pelaporan dengan efektif dan efisien. Pada sistem yang diusulkan ini memerlukan beberapa tahapan yang terlihat seperti pada gambar 4.2. Bendahara memberikan data rencana penggunaan dana Bantuan Operasional Sekolah kepada Tata Usaha.

1) Tata Usaha memberikan data rencana penggunaan dana Bantuan Operasional Sekolah dari bendahara yang kemudian diinputkan kedalam sistem dengan menggunakan aplikasi peaporan BOS, data 
yang diinput tersimpan kedalam pelaporan BOS.

2) Laporan yang telah dibuat kemudian dicetak rangkap tiga dan diperiksa apakah laporan tersebut telah sesuai kebenarannya. Jika laporan belum sesuai maka kepala sekolah memberikan data rencana penggunaan dana BOS ke bendahara. Kemudian bendahara memberikan laporan tersebut kepada tata usaha untuk diinput kembali. Jika laporan telah valid maka laporan tersebut dicetak rangkap tiga, kemudian diserahkan kepada bendahara, kepala sekolah, dan satu sebagai arsip dibagian tata usaha.

\subsection{Diagram Konteks}

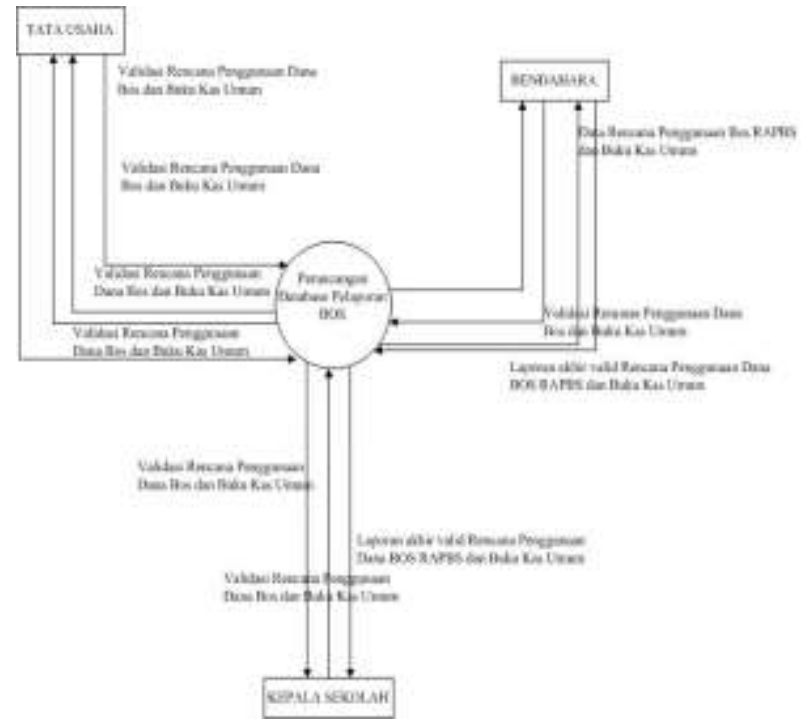

Gambar 4.3 Diagram Konteks

\subsection{Data Flow Diagram (DFD) level 1}

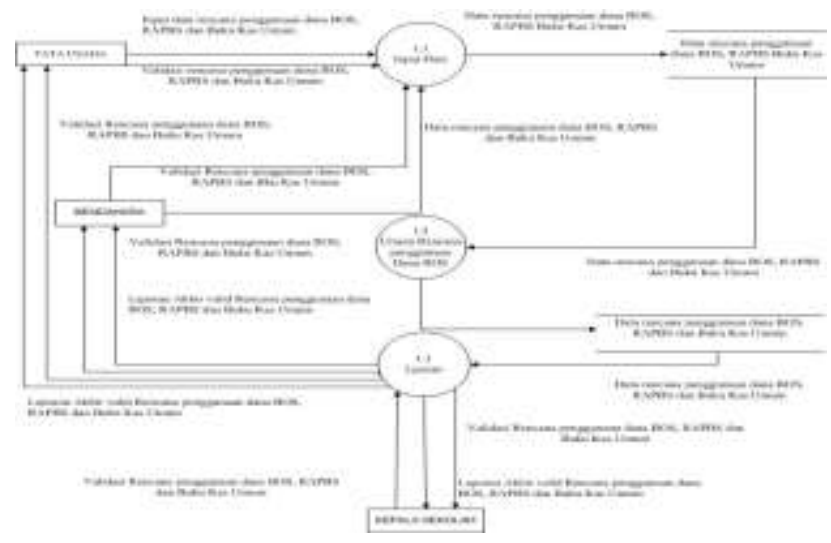

Gambar 4.4 DFD Level 1
Penjelasan DFD Level 1:

1) Bendahara memberikan data rencana penggunaan dana BOS yang berupa RAPBS, Buku Kas Umum, Buku pembantu Pajak, Buku Pembantu Bank, Buku Pembantu Tunai kepada tata usaha yang akan di input ke aplikasi plaporan BOS. Data RAPBS, Buku Kas Umum, Buku pembantu Pajak, Buku Pembantu Bank, Buku Pembantu Tunai yang sudah di input akan tersimpan didalam Database Sistem Informasi Pelaporan dana BOS, sehingga komputer juga dapat mengakses data yang sudah terdapat dalam Database Sistem Informasi Pelaporan dana BOS.

2) Aplikasi menguraikan data rencana penggunaan dana BOS yang berupa RAPBS, Buku Kas Umum, Buku pembantu Pajak, Buku Pembantu Bank, Buku Pembantu Tunai. Proses input data (yang diambil dari Database) dimasukkan kedalam komputer dihasilkan data uraian penggunaaan dana BOS yang berupa RAPBS, Buku Kas Umum, Buku pembantu Pajak, Buku Pembantu Bank, Buku Pembantu Tunai.

3) Data-data yang terdapat pada file Database penggunaan dana BOS yang berupa RAPBS, Buku Kas Umum, Buku pembantu Pajak, Buku Pembantu Bank, Buku Pembantu Tunai. Diproses kembali sehingga menghasilkan laporan valid yang kemudian dicetak rangkap tiga. Kemudian diserahkan kepada Bendahara, Kepala Sekolah, dan satu sebagai arsip dibagian Tata usaha.

\subsection{Entity Relationship Diagram}

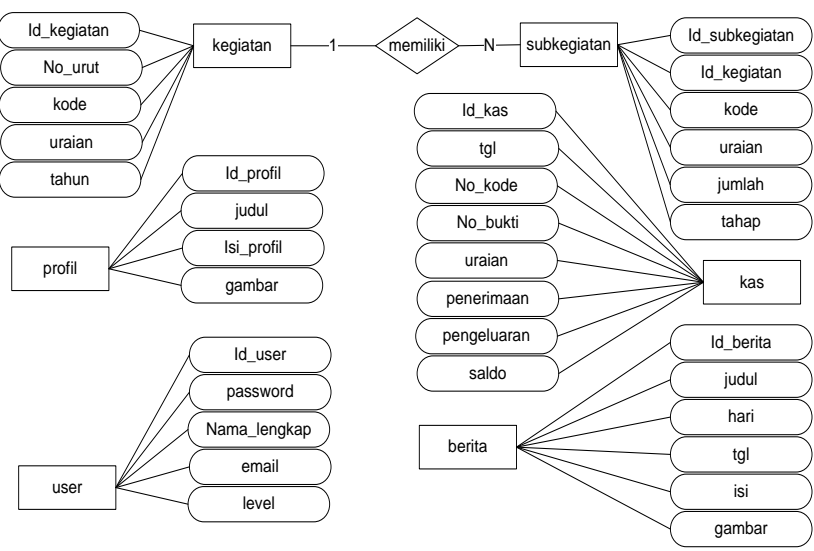

Gambar 4.5 ERD 


\section{Implementasi dan Pembahasan} Halaman Utama

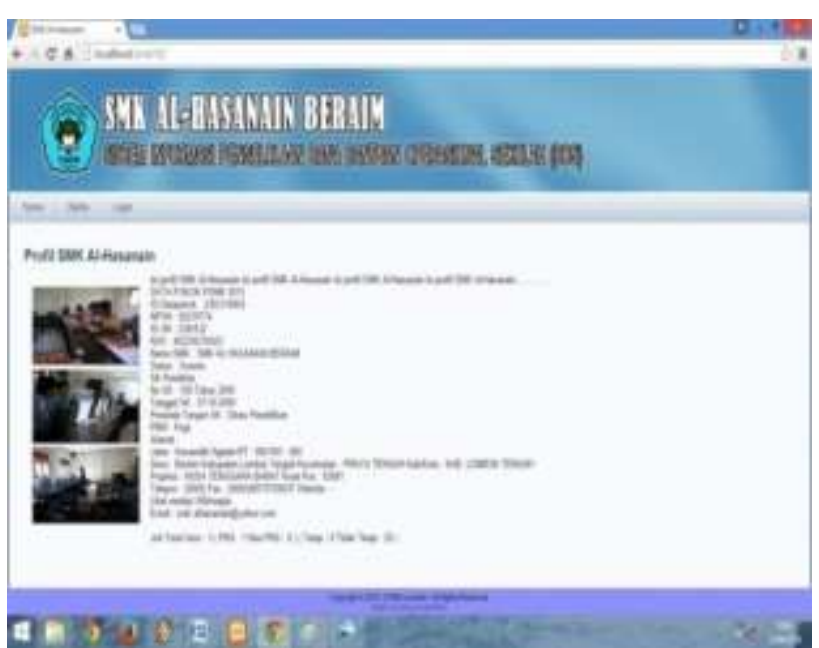

Gambar 5.1. Halaman Utama

Antar muka yang dibuat dalam implementasi ini dibagi menjadi 2 (dua) berdasarkan user, yakni admin dan user biasa (Tata usaha).

\section{Halaman Login Admin}

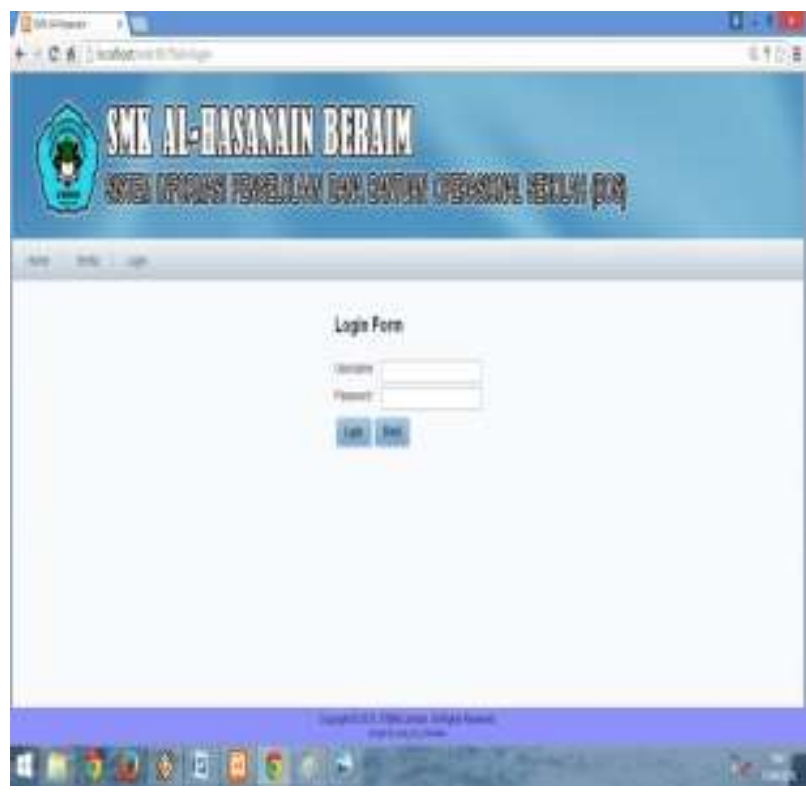

Gambar 5.2 Halaman login admin

Login merupakan tampilan awal yang harus dilalui untuk memulai pekerjaan. Proses login akan membawa penguna/user dan admin pada masing-masing halaman yang telah dikategorikan. Halaman ini digunakan untuk masuk ke sistem dan membedakan level user beserta hak aksesnya.

\section{Halaman Utama Admin setelah Login}

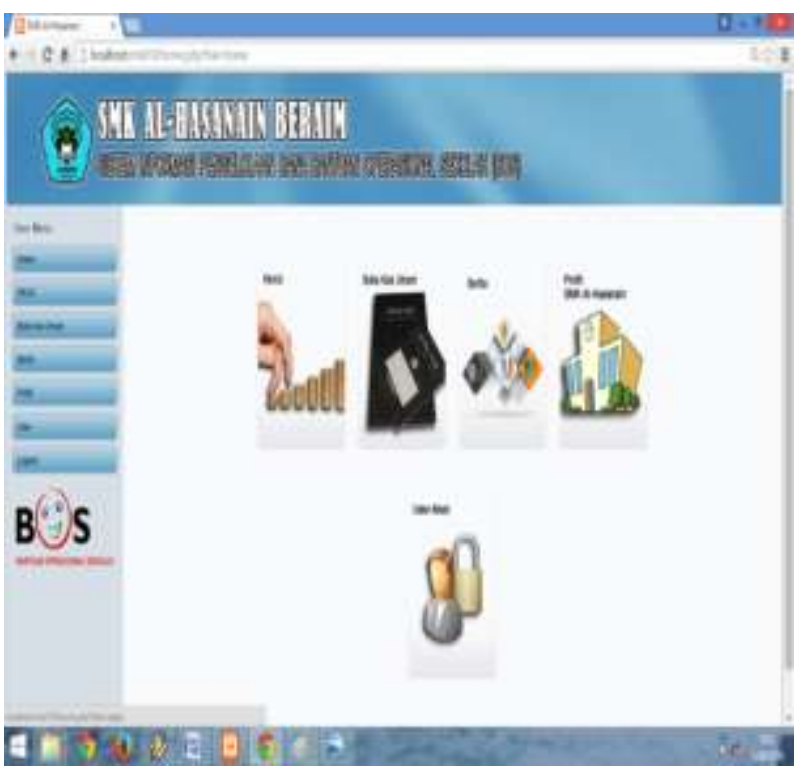

Gambar 5.3 Halaman utama admin

Dalam menu utama admin, terdapat 7 menu dengan masing-masing submenunya. 7 menu tersebut adalah menu: home, RKAS, buku kas umum, berita, profil, user dan logout dimana menu utama ini berfungsi sebagai jembatan antara pengguna dengan system.

\section{Halaman tambah data user}

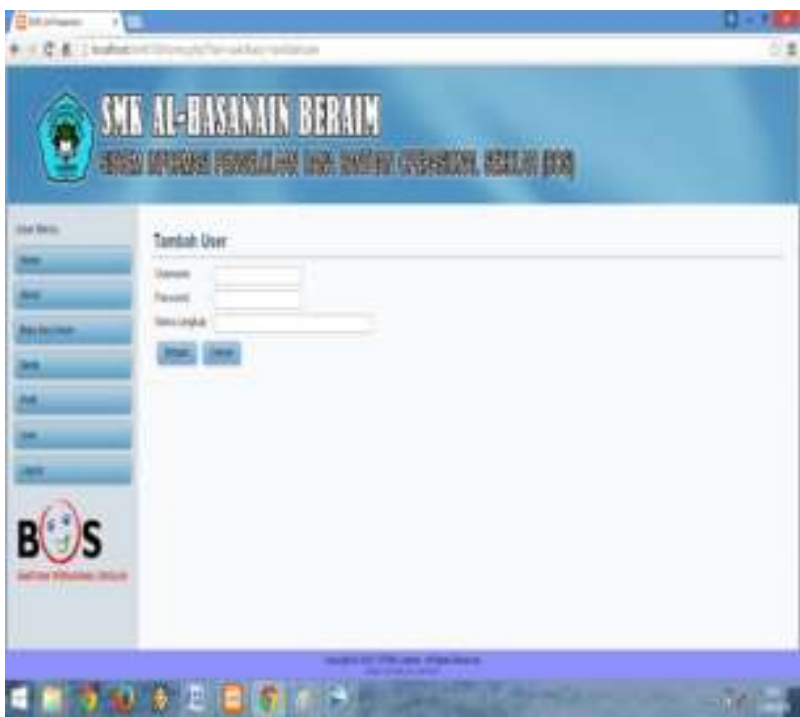

Gambar 5.4 Halaman tambah user

Halaman data admin ini merupakan daftar admin dari sistem ini kita dapat menambah user admin dengan mengisikan user, password, nama 
seperti terlihat pada gambar kemudian clik tambah data untuk membuat user baru.

\section{Halaman RKAS Admin}

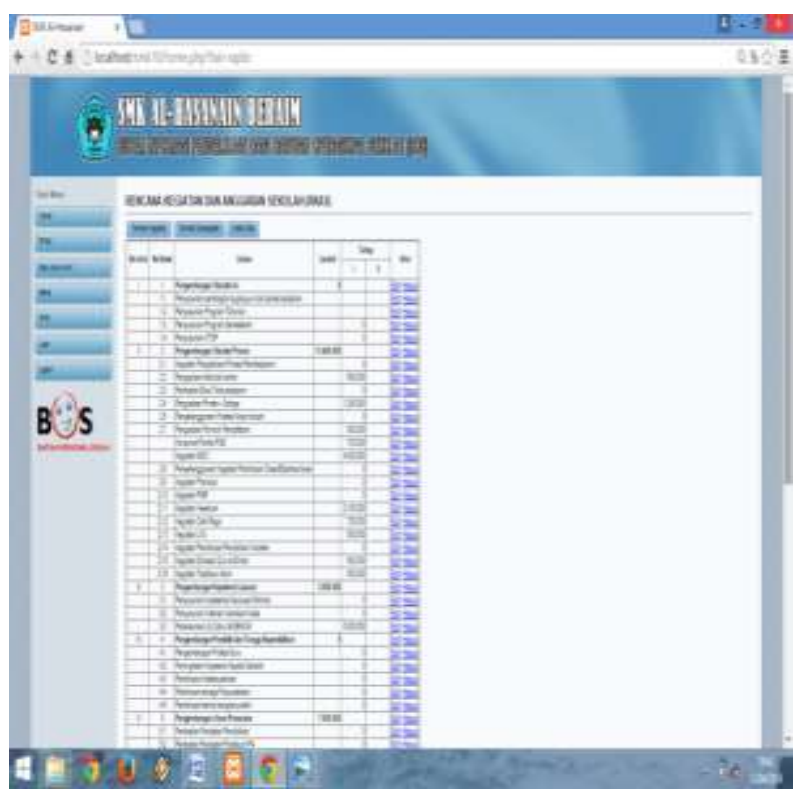

Gambar 5.5 Halaman RKAS admin

Halaman data RKAS ini adalah halaman yang digunakan untuk penyusunan data pengajuan barang yang dilakukan setiap awal tahun atau semester, untuk perincian pemakaian dana bantuan operasional sekolah selama satu tahun.

\section{Halaman Buku Kas Umum Admin}

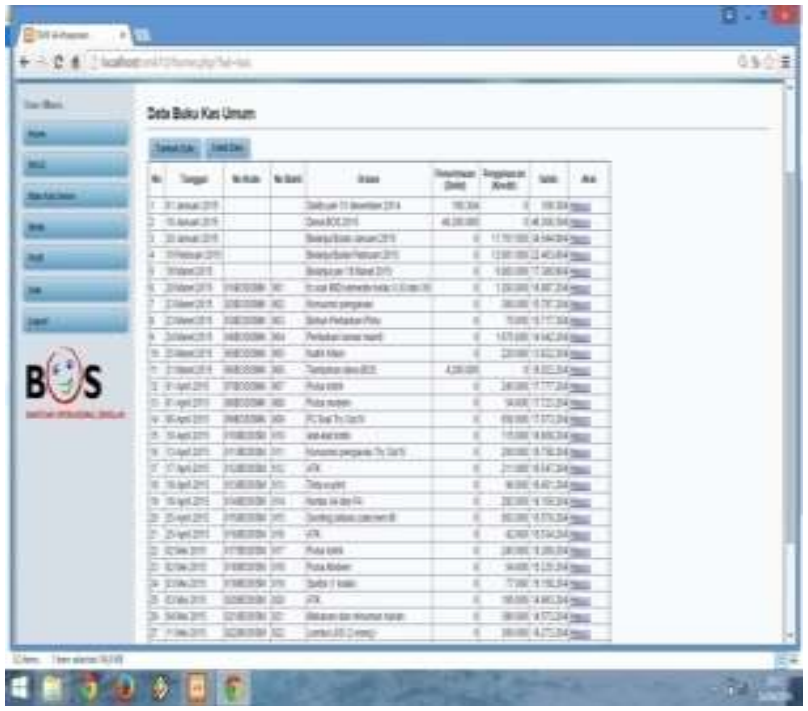

Gambar 5.6 Halaman BKU admin

Halaman data BKU ini adalah halaman yang digunakan untuk rekapitulasi dana atau saldo keuangan dana BOS untuk halaman admin ini bisa melakukan edit dan hapus.

\section{Penutup}

\subsection{Kesimpulan}

1) Sistem informasi ini dapat membantu sekolah dalam proses penyusunan RKAS setiap tahun.

2) Sistem informasi ini dapat membantu sekolah dalam penyusunan realisasi pelaporan penggunaan dana bantuan operasional sekolah setiap triwulannya dalam bentuk BKU.

3) Aplikasi ini dapat memudahkan admin dalam pengecekan dana bantuan operasional sekolah yang telah dianggarkan.

4) Aplikasi ini sangat membantu dengan model pelaporan manual merepotkan pihak sekolah dan dinas, dikemas dalam bentuk sistem berbasis web.

\subsection{Saran}

1) Agar dilakukan sosialisasi terhadap program ini kepada intansi yang bersangkutan. Dilakukan peningkatan fitur sesuai dengan kebutuhan yang ada.

2) Pengembangan berikutnya adalah sistem Informasi ini dikelola dalam server online.

\section{Daftar Pustaka}

Jogiyanto, 2005, Analisis \& Desain Sistem Informasi Pendekatan Terstruktur Teori dan Praktek Aplikasi Bisnis:Yogyakarta

Jogiyanto, 2008, Sistem Teknologi Informasi, Edisi Ketiga, Andi:Yogyakarta

Kemdiknas, 2010, Buku Panduan Bantuan Operasional Sekolah (BOS) Untuk Pendidikan Gratis dalam Rangka Wajib Belajar 9 Tahun yang Bermutu

Ladjamudin Bin Al-Bahra, 2005, Analisis dan Desain Sistem Informasi, Edisi Pertama, Graha Ilmu:Yogyakarta

Mudrikah Isnaini Nurul, 2013, Pembuatan aplikasi laporan dana BOS pada SDN 
Sidorejo Kecamatan Kalasan Kabupaten Sleman

Petunjuk Teknis, 2015, Bantuan Operasional Sekolah (BOS)

Prasetyo Dwi Agustinus, 2010, Sistem Laporan Penggunaan Dana Bantuan Operasional Sekolah Pada Sekolah Dasar Kabupaten Sleman
Wulandari Asri Anggraini, dkk, 2008, Aplikasi Pengelolaan Dana BOS (Bantuan Operasional Sekolah) Berbasis Web Based Application Of School Operation Fund's Management. Jurnal Telkom Comunity 